\title{
El turismo urbano y la geografía de la ciudad*
}

\begin{abstract}
For post-structuralist urban literature, cities appear as landscapes fractured in protected and exclusionary enclaves, which colonize and replace local places. Consequently, it is considered that tourist enclaves facilitate the authoritarian control of urban space, modifying the consumption and replacing and suppressing local culture with Disney-like environments. This article argues that, even when within tourist enclaves a non-democratic, directive and authoritarian regime is attempted -and generally achieved-, in this spaces social control in not complete; the analysis that this article proposes of tourist spaces reveals that the fracture of post-modern metropolises spaces is able to create diversity and difference, more than monotony and uniformity. It is conclude that, for the city visitors, the urban dystopia predicted by post-structuralist scholars has not been materialized yet.
\end{abstract}

Key words: tourist enclaves, social control, post-structuralist urbanism, urban theory.

\section{Resumen}

Para la literatura urbana post-estructuralista, las ciudades aparecen como paisajes fracturados en enclaves protegidos y excluyentes, los cuales colonizan y reemplazan los lugares locales. Consecuentemente, se considera que los enclaves turísticos facilitan el control autoritario del espacio urbano, modificando el consumo y reemplazando y suprimiendo la cultura local con "ambientes Disney". Este artículo plantea que si bien dentro de los enclaves turísticos se intenta -y generalmente se alcanza- un régimen no democrático, directivo y autoritario, incluso en estos espacios el control social no es total; el análisis que aquí se propone respecto de los espacios turísticos revela que la fractura de los espacios de las metrópolis postmodernas puede crear diversidad y diferencia, más que monotonía y uniformidad. Se concluye que, para los visitantes de las ciudades, la distopia urbana predicha por los post-estructuralistas no ha sido aún materializada.

Palabras clave: enclaves turísticos, control social, urbanismo post-estructuralista, teoría urbana. 


\section{Introducción}

E $n$ años recientes, ha emergido una literatura que describe la ciudad presente y futura como un paisaje fracturado en enclaves protegidos, rodeados de áreas fuertemente vigiladas, ocupadas por los pobres y los marginados. Esta visión es particularmente cercana a la Escuela de Los Ángeles, la cual ha considerado su objeto de estudio, la conurbación de Los Ángeles, como representativa de lo que las ciudades son actualmente, o de lo que están destinadas a ser. Ed Soja (1989) ha afirmado, por ejemplo, que Los Ángeles "se presenta insistentemente como uno de los palimpsestos y paradigmas más reveladores del desarrollo urbano del siglo XX y de la conciencia popular, el único lugar en la Tierra donde todos los lugares son vistos desde cada ángulo, cada uno destacándose claramente, sin ninguna confusión o mezcla" (248). En su relato sobre el surgimiento de la Escuela de Los Ángeles, Michael Dear (2002) aclara que Los Ángeles revela la trayectoria del desarrollo urbano en todo el mundo: "El lujo se combina con una matriz de miseria empobrecida; la segura comunidad autocontenida y el hogar fortificado pueden ser encontrados primero en lugares como Manila y Sao Paulo" (14); continúa sugiriendo que estos elementos han aparecido más recientemente en Los Ángeles, y últimamente -puede presumirse- en la mayoría de los lugares urbanos en el mundo.

La literatura urbana post-estructuralista ${ }^{1}$ concibe los enclaves como nodos de circuitos internacionales del capital y la cultura, los cuales están colonizando y reemplazando a los lugares locales. Según la describe Michael Sorkin (1992), "la nueva ciudad reemplaza la anomalía y el encanto de los lugares [locales] con un universal particular, un urbanismo genérico conjugado sólo con un appliqué" (xiii).

\footnotetext{
University of Illinois at Chicago. E-mail: djudd@uic.edu

* Traducido por Diego Campos.
}

En su relato, esta nueva ciudad se caracteriza por "niveles crecientes de manipulación y vigilancia" y "nuevas formas de segregación" puestas al servicio de una "ciudad de simulaciones, la ciudad de la televisión, la ciudad como un parque temático" (xiii-xiv). David Harvey (1994) reitera la preocupación, frecuentemente expresada, acerca de que las ciudades están siendo transformadas en copias sanitizadas y monótonas unas de otras, "prácticamente idénticas de ciudad en ciudad” (295).

De acuerdo a los investigadores urbanos, los enclaves turísticos facilitan el control autoritario del espacio urbano, modificando el consumo y reemplazando y suprimiendo la cultura local con "ambientes Disney". Tim Edensor (1998) reitera la observación de Lefebvre (1991) acerca de que los espacios turísticos "son planificados con el mayor cuidado: centralizados, organizados, jerarquizados, simbolizados y programados al enésimo grado" (384). De modo similar, John Hannigan (1998) afirma que la uniformidad de los espacios que habitan los turistas los sujeta a "una forma de experiencia urbana medida, controlada y organizada" (6), que elimina la impredecible calidad de la vida callejera cotidiana.

He escrito previamente acerca del surgimiento de las burbujas turísticas estandarizadas y producidas en masa, que "crean islas de riqueza marcadamente diferenciadas y segregadas del paisaje urbano circundante" (Judd, 1999:

Sigo el ejemplo de Susan Fainstein (2001) en el empleo de este término para denotar un cuerpo de investigadores que enfatizan lo que a menudo es calificado como "geografía post-moderna" de la ciudad, la cual es descrita como un paisaje fracturado por muros, barreras y una geografía de la diferencia y la separación, una forma de desarrollo producida por las influencias económicas y políticas de la globalización. Esta visión constituye un marcado distanciamiento de una geografía "modernista" del siglo $X X$, de la planificación comprehensiva, el desarrollo a gran escala y el objetivo de lograr el orden y la armonía en el ambiente urbano. La interpretación postestructuralista del desarrollo urbano es representada bastante auto-conscientemente por la Escuela de Los Ángeles (ver Dear, 2002). 
53). Creo que esta descripción es todavía precisa, pero los enclaves turísticos constituyen solamente una parte del ambiente que los turistas urbanos experimentan. Los enclaves turísticos se han transformado en rasgos ubicuos de las ciudades, pero no las aplastan inexorablemente. En el examen del carácter espacial del turismo urbano, la escala del análisis resulta fundamental. Dentro de los enclaves turísticos, se intenta $-y$ generalmente se alcanzaun régimen no democrático, directivo y autoritario, aunque, como argumentaré, incluso en estos espacios el control social no es total. Pero cuando el turismo urbano es considerado a la escala de la ciudad, en la mayoría de éstas los enclaves capturan sólo a algunos de los visitantes, durante sólo una parte del tiempo. Para los visitantes de las ciudades, la distopia urbana predicha por los post-estructuralistas no se ha materializado.

\section{La construcción histórica de los enclaves turísticos}

Hasta el surgimiento del turismo masivo en la segunda mitad del siglo XIX, las ciudades ostentaron un status espacial como destinos de los viajes. Las ciudades del Grand Tourde los siglos XV al XVIII -principalmente París, Génova, Roma, Florencia, Venecia y Nápoles-eran visitadas como un rito de pasaje por hombres jóvenes pertenecientes a las clases altas británicas, de quienes se esperaba que alcanzaran la mayoría de edad viendo "las ruinas de la Roma clásica, así como también las iglesias y sitios y colecciones de arte de las grandes capitales del Continente" (Withey, 1997: 7). Las ciudades del Grand Tour ofrecían tanto un barniz de alta cultura como diversiones mundanas, pero eran también denostadas. Como la historiadora Lynne Withey ha observado, los signos de pobreza, desorden social y deterioro físico eran evidentes por todas partes en Roma, Nápoles y Venecia, y París era un caos de calles sobrepobladas, llenas de caballos y carros tambaleantes, cubiertas de basura y recorridas por desagües y cloacas.
A pesar de los inconvenientes de las ciudades del Grand Tour, los viajeros estaban dispuestos a soportar semanas de incomodidad para franquear caminos estrechos y montañas casi intransitables a fin de llegar a ellas. Los peligros y las molestias del viaje dieron forma a un generalizado desdén por la naturaleza y por lo natural. Las montañas eran consideradas feas y desagradables, las costas generalmente inaccesibles y peligrosas. A mediados del siglo XVIII, sin embargo, tales actitudes comenzaron a cambiar. La naturaleza fue descubierta como un vasto depósito de panoramas y vistas. Los poetas románticos reinterpretaron la naturaleza como un manso telón de fondo de frondosas ramadas, árboles majestuosos y plácidos lagos. Con el surgimiento de las ciudades industriales del siglo XIX, floreció un culto por la naturaleza, ahora interpretada a través de Thoreau, Wordsworth y sus contemporáneos como el depósito del espíritu humano, opuesto a la crueldad y oscuridad de las ciudades.

El "gran tour americano" de los años posteriores a la Guerra Civil se estableció en marcado contraste con su contraparte europea anterior, con viajes por los valles de los ríos Hudson y Connecticut como "ejemplos principales de lo pintoresco", y las Montañas Catskill y las Cataratas del Niágara como ejemplos íconos de lo "sublime" (Withey, 1997: 117). Pero los europeos también visitaban lugares como St. Louis, Cincinnatti y Chicago para constatar la evidencia dramática del progreso y la industria. Observaban los grandes hoteles y mansiones, botes y barcos de vapor, inmigrantes recién llegados e incluso a veces ocasionales indios, todo ello combinado en "una curiosa mixtura de lo civilizado y lo primitivo" (Withey, 1997: 131). Las élites urbanas estaban convencidas de que las percepciones de los visitantes podían determinar las perspectivas económicas de una ciudad, y en consecuencia promovieron éxitos culturales, educacionales y artísticos, reales e imaginados.

Las ciudades europeas renacieron como destinos turísticos transformándose en las 
paradas de una versión democratizada del Grand Tour. En la década de 1850, Thomas Cook inició la época del turismo masivo conduciendo paquetes turísticos al continente. Las ciudades se promovían como tales, aunque más como centros industriales que de cultura. La glorificación de la tecnología y el progreso proporcionaron un hilo conductor a través de las ferias y exhibiciones del siglo XIX y primeras décadas del siglo $\mathrm{XX}$ : la exposición del Cristal Palace en Londres de 1851 y la Exhibición de París de 1867; y cruzando el océano, la Feria Mundial de Chicago en 1893, St. Louis en 1904 y Nueva York en 1938.

Pero tales actividades promocionales no fueron suficientes para transformar a las ciudades en destinos turísticos. Las ciudades de la época industrial eran tenidas en cuenta más a menudo por sus barriadas miserables y problemas sociales que por sus tesoros arquitectónicos y culturales (Hall, 1996). Un visitante que eligiera viajar azarosamente por las calles de la ciudad podría haber tenido muchas aventuras, pero no todas habrían sido bienvenidas. El turismo urbano se desarrolló junto con las demarcaciones de los sitios y vistas que los visitantes debían conocer. Cuando Thomas Cook comenzó a ofrecer paquetes turísticos a ciudades europeas, se hizo cargo de sitios históricos y atracciones culturales, disponiendo el alojamiento y proveyendo información y asistencia esenciales (Urry, 1990). Para 1869 condujo a los primeros turistas a Jerusalén y a Tierra Santa, un negocio que creció rápidamente (a través de Thomas Cook \& Son) a cinco mil visitantes por año en una década.

Los paquetes turísticos desmitificaban los lugares visitados, disgregándolos en partes manejables, cada una de las cuales era portadora de importancia y significado. Para el cambio de siglo la mayoría de las principales ciudades europeas habían sido interpretadas de esta manera a través de guías de viaje, y los servicios de guías turísticos habían florecido hasta competir con Cook. En Estados Unidos evolucionó un proceso paralelo, en el cual los empresarios turísticos locales tomaron la delantera. Guías de viaje, bosquejos, dibujos y fotografías "entrenaban" a los visitantes respecto de qué ver y qué hacer. Las representaciones y los espacios físicos "jugaron un papel clave tanto en atraer a los turistas como en trasmitir un sentimiento de unidad social" (Cocks, 2001: 144). Los operadores turísticos locales tradujeron las descripciones y representaciones encontradas en guías de viaje en realidades físicas, proporcionando a los turistas itinerarios fijos, los cuales reducían las ciudades que veían a una melànge de monumentos, sitios históricos y centros culturales. La experiencia turística en el transporte masivo y los recorridos guiados redujeron la ciudad a un panorama de "ciudad de paso" vista "desde fuera, de una manera fascinante" (Cocks, 2001: 164). Las Ferias Mundiales y exhibiciones consolidaron el hábito de ver a las ciudades como un collage de imágenes urbanas estilizadas y escenas preestablecidas. Como observó un visitante acerca de la Exposición Colombina Mundial en la Feria Mundial de Chicago de 1982, "la Feria es un mundo [...] del cual la fealdad y la inutilidad han sido extirpadas, y sólo la belleza y la utilidad admitidas" (Cocks, 2001: 128). El movimiento de la City Beautiful derivó gran parte de su inspiración de la Feria Mundial de Chicago, con su atención puesta en la arquitectura monumental, parques y espacios públicos.

Algunas décadas después, se desplegó un proceso similar de construcción de imagen y reconstrucción espacial. Hacia la década de 1960, en Estados Unidos las antiguas ciudades industriales se vieron enfrentadas al deterioro físico de los downtowns y la diseminación de la ruina a través de millas de barrios alrededor del núcleo central. Los proyectos masivos de "limpieza" financiados por la renovación urbana fracasaron en la producción de un renacimiento urbano, y todas las mejoras introducidas por los programas federales de concesiones fueron ensombrecidas por el crimen, las revueltas y los disturbios sociales. Los candidatos republicanos y los medios de comunicación retrataban a las ciudades como lí- 
neas de fuego de la violencia y los problemas raciales, de modo que términos como gueto, asistencia social, infraclase, crimen e innercity constituyeron un todo de imágenes intercambiables (Edsall \& Edsall, 1991). Como resultado, la narrativa del declive urbano penetró la conciencia nacional, borrando en su mayor parte las imágenes positivas que las ciudades habían heredado del pasado (Beauregard, 1993).

Aquellos que se proponían hacer estas ciudades atractivas para los turistas se enfrentaron a un intimidante desafío. Había dos problemas igualmente serios. En primer lugar, el "imaginario urbano" de los potenciales turistas tenía que ser cambiado. Y en segundo lugar, el actual ambiente físico de las ciudades con problemas tenía que ser transformado en lugares de belleza, interés y emoción. En las ciudades más antiguas, la burbuja turística se transformó en la solución a ambos problemas. Durante las décadas de 1980 y 1990, una concentración de instalaciones y servicios (nuevos frentes de agua, hoteles, festival malls, centros de convenciones, estadios deportivos y "distritos de entretenimiento") fue construida para crear un espacio o series de espacios segregados del resto de la ciudad. Incluso si ocupaban sólo una pequeña parte del total de la estructura urbana, estos espacios proporcionaron imágenes de una ciudad renacida. $Y$ mediante la construcción de espacios fortificados, hasta las ciudades con altos niveles de criminalidad fueron capaces de generar islas y reservaciones que pudieran ser habitadas cómodamente por turistas y residentes de clase media. Al interior de estas islas emergió una atmósfera como de carnaval para satisfacer la necesidad de emoción.

\section{Control social al interior de los enclaves turísticos}

El análisis de Baudrillard (1998) respecto de los lugares de consumo como campos culturales conformados por "una totalidad mar- cada por el consumo" es útil para entender cómo los administradores de los enclaves turísticos pueden intentar regular sus usos. Baudrillard escribe que los shopping centers son lugares en los cuales "el arte y el ocio se mezclan con la vida cotidiana" y constituyen, en efecto, subculturas que establecen por sí mismas un contexto perfecto para el consumo a través del "total condicionamiento de la acción y el tiempo" (28-29). Permiten la mezcla del deseo y la saciedad en una ardiente mixtura, en la cual todas las sensaciones se ven arrolladas por un Pandemoniun conformado por "una amplia vista del perpetuo consumo" (30). Los enclaves turísticos pueden operar de manera similar, envolviendo a los visitantes en un ambiente que inunda sus sentidos con los signos y símbolos del consumo y el juego.

Tales experiencias pueden ser concebidas como dando cuerpo a un ambiente totalizante que filtra las percepciones, experiencias y deseos de los turistas. Los turistas que habitan espacios enclávicos son animados a actuar esencialmente como obreros de una factoría sujetos a "un horario, a un controlador del tiempo, a informantes y multas" (Thompson, 1967). Por cuanto se encuentran limitados por barreras físicas y son destinados a actividades especializadas, ciertos lugares como los estadios deportivos, centros de convenciones y malls pueden efectuar una regulación casi total del cuerpo. Los estadios deportivos y los centros de convenciones, por ejemplo, están diseñados para el solo propósito de la representación, y los usuarios que tienen otras actividades en mente son aptos sólo para ser arrojados fuera. De manera similar, los shopping malls son construidos como palacios del consumo; la vagancia sin rumbo es disuadida o prohibida. Aunque a veces se hacen pasar por espacios públicos, tales ambientes confinados proyectan un "aspecto finito o acabado" que todo lo dirige hacia su interior (Lefebvre, 1991: 147).

Los espacios turísticos enclávicos están diseñados para regular a sus habitantes a través del control de cuatro aspectos princi- 
pales de la agenda: el deseo, el consumo, el movimiento y el tiempo. El deseo y el consumo son regulados por la promoción y el marketing. El tiempo y el movimiento están estrictamente confinados (por pasillos, torniquetes de acceso, escaleras mecánicas, túneles y galerías) y monitoreados (por cámaras y guardias de seguridad). El uso del tiempo es también delimitado por la programación de espectáculos y representaciones y por características físicas como la disponibilidad o ausencia de asientos y lugares de reunión. Las experiencias y productos en oferta combinan la homogeneidad y la heterogeneidad, suficiente tanto para dar un sentido de comodidad y familiaridad como para inducir también un sentido de novedad y sorpresa.

Excepto aquellas promovidas por los auspiciadores corporativos, otras actividades son a menudo interceptadas o denegadas. Los malls prohíben rutinariamente actividades políticas o de cualquier otro tipo, y las fuerzas de seguridad son rápidas en escoltar a los conspicuos no-consumidores fuera de las instalaciones. El modo en que esto opera pudo ser percibido en la apertura del World Financial Center en Nueva York, en octubre de 1998. El agente publicitario contratado por el desarrollador, Olympia \& York, puso en escena cinco días de celebraciones, proyectados para transmitir (en el lenguaje publicitario de la firma) "una comprensión progresiva de los usos del espacio público". Mientras transcurrían, las celebraciones se mantuvieron fuertemente ligadas a las necesidades de marketing de los negocios localizados en el Centro. Las actividades publicitarias definieron y limitaron estrictamente las actividades de los participantes, quienes fueron reducidos al status de observadores pasivos (Boyer, 1994: 486).

Si las ciudades estuvieran principalmente compuestas de archipiélagos y enclaves, los visitantes y habitantes locales encontrarían dificultades para escapar de la estrecha vigilancia y control que los espacios enclávicos facilitan. Sin embargo, los enclaves constituyen sólo uno de los componentes de la espa- cialidad crecientemente compleja del turismo urbano. Los ambientes habitados por los visitantes de las ciudades recorren todo el espectro, desde los espacios construidos específicamente para la producción del espectáculo y el consumo, hasta espacios públicos como frentes de agua, parques y plazas, pasando por comercios y calles residenciales. Esta compleja geografía proporciona muchas oportunidades a los visitantes para escapar de los confines del encierro.

\section{La compleja estructura espacial del turismo urbano}

Algunas antiguas ciudades industriales y portuarias en Estados Unidos e Inglaterra han compartido una trayectoria que parece confirmar las extremas predicciones de los investigadores post-estructuralistas: un marcado declive durante la desindustrialización de las décadas de 1970 y 1980 , seguido por una suerte de revitalización que segmentó bruscamente el espacio urbano, en beneficio de una próspera clase media y en detrimento de los pobres (Judd \& Parkinson, 1990).

Baltimore es emblemática de este tipo de re-desarrollo. Su afamado Harbor Place -con sus amplios mármoles y plazas duras, un mall, un acuario, restaurantes y bares y varios hoteles de lujo- es una virtual reservación para visitantes que raramente experimentan el resto de una ciudad en problemas (Huka, 1990; Harvey, 2001). Del mismo modo, excepto por las torres gemelas cilíndricas del Renaissance Center y el mall cercano llamado Greektown, Detroit es hostil a los visitantes. Las Vegas es un tipo diferente de ciudad turística, pero resulta igualmente segmentada. The Strip, con sus luces de neón, sus interpretaciones falsificadas del skyline de Nueva York y del Antiguo Egipto y entretención durante las 24 horas del día, proporciona un vistazo voyerista de una ciudad que ha sido construida como una fachada de carnaval y espectáculo (Rothman \& Davis, 2002). Los visitantes tendrían pocas razones para recorrer más allá del Strip. 
Pero estas ciudades-mentira no son típicas, y no constituyen necesariamente presagios de lo que todas las ciudades están destinadas a ser, como cualquier viajero que pase por ciudades en Estados Unidos, Europa y muchos otros lugares puede atestiguar. Boston, por ejemplo, es una ciudad peatonal para residentes y visitantes por igual, a pesar de la presencia de un gran mall en el frente de agua en Faneuil Hall y un mall y un complejo hotelero interconectados en el centro de la ciudad, en Copley Plaza (Ehrlich \& Dreier, 1999). Las calles que están afuera de estos recintos están atestadas de residentes locales y visitantes, y éstos se dispersan libremente en los negocios y áreas residenciales lejanas desde hace más de una década. Del mismo modo, los visitantes no son confinados al interior de espacios cercados en la mayoría de las ciudades de Estados Unidos o de cualquier ciudad en Canadá o Europa. Una experiencia como ésta recibe a los visitantes sólo en las ciudades más peligrosas y con los mayores niveles de criminalidad del mundo.

Los enclaves son generalmente incorporados en una textura urbana que se ha convertido en un objeto de fascinación y consumo en sí misma. Como Sassen y Roost (1999) han observado, "la gran ciudad ha asumido el status de exótica. El turismo moderno ya no está centrado en los monumentos históricos, las salas de concierto o los museos, sino en la escena urbana, o más precisamente, en alguna versión de la escena urbana adecuada para el turismo" (143). La "escena" que los visitantes consumen está compuesta por un calidoscopio de experiencias y espacios orientados al trabajo, consumo, ocio y entretención (Featherstone, 1994). Las áreas de las ciudades que invitan a los turistas a deambular pueden no ser lugares normalmente habitados por turistas; pueden ser áreas "tensas" -barrios fronterizos o zonas donde pueden vivir y trabajar personas ubicadas en los márgenes de la sociedad urbana: minorías étnicas, no-blancos, inmigrantes, pobres. Tales áreas pueden ser atractivas precisamente porque no han sido construidas ni dispuestas para los turistas.
Afuera de la habitual zona cómoda, los turistas pueden pasear en un espacio intelectual y físico interesante e impredecible. Como lo expresa un artista que vive en un barrio de este tipo, "junto con el peligro hay una vitalidad que uno pierde; cuando se está tan confiado respecto de la seguridad personal hay un cierto límite que se disipa. $Y$ hay algo emocionante en ese límite" (Lloyd, 2000: 33).

En las ciudades europeas que no han experimentado los extremos de la segregación, el crimen, las tensiones raciales y los problemas sociales de algunas ciudades antiguas de Estados Unidos y de países en desarrollo, los visitantes tienden a ser absorbidos en la estructura urbana. Leo van den Berg (2003) y sus colaboradores han propuesto la existencia de un "modelo europeo" que acentúa el "desarrollo armónico de la ciudad" más que la construcción de espacios turísticos segregados. Sus estudios sobre Rótterdam, Ámsterdam, Lisboa y Birmingham demuestran que en estas ciudades, los planificadores y quienes diseñan políticas públicas sopesan los costos del turismo tomando en consideración "los desplazamientos de las actividades orientadas a los residentes, la gentrificación y las fricciones culturales" (van den Berg, 2003).

Un equilibrio de esta naturaleza entre las necesidades locales y los proyectos de desarrollo económico requieren una visión política de largo alcance, difícilmente posible en ciudades cuyos líderes se sienten desesperados por lograr el desarrollo a cualquier costo. En las ciudades europeas, la herencia arquitectónica y cultural única de los núcleos urbanos ha sido entendida como la principal atracción para los visitantes; en consecuencia, el desarrollo turístico ha apuntado a realzar el carácter de cada ciudad. De manera similar, los planificadores en Vancouver han considerado al turismo como el producto natural de políticas que enfatizan los barrios, servicios urbanos y el medio ambiente (Artibise, 2003). Ni siquiera en Montreal, una ciudad que ha privilegiado megaproyectos tales como la Expo 67 (la Feria Mundial de 1967) y las Olimpíadas de Ve- 
rano de 1976, así como otros grandes proyectos, se han desarrollado burbujas turísticas; sus visitantes a menudo deambulan por el downtown y los barrios (Levine, 2003). Ciudad de México es un caso interesante, por cuanto ha focalizado sus energías en el desarrollo de un enclave en el centro histórico, una estrategia virtualmente forzada por los altos niveles de criminalidad de la ciudad. Pero a pesar de estas condiciones, los planificadores están tratando de hacer de este enclave un lugar atractivo tanto para los residentes locales como para los visitantes (Hiernaux-Nicolás, 2003).

La cambiante geografía de la estructura espacial urbana refleja el surgimiento de una cultura urbana que gira en torno a la preocupación por la "calidad de vida" (Lloyd, 2000). Es cada vez más difícil distinguir a los espacios para los visitantes de aquellos espacios "locales", dado que los sectores de ocio, entretención y cultura son considerados como cruciales tanto por residentes locales como por visitantes forasteros. Cuando no están viajando, los residentes locales se involucran en actividades indistinguibles de lo que hacen los turistas: salir a comer, ir al mall, caminar por la costanera, asistir a un concierto. El surgimiento de una nueva cultura urbana orientada a la búsqueda estética ha reconstruido a las ciudades como lugares que proporcionan oportunidades para viajar desde la propia casa: "Los consumidores ya no tienen que viajar grandes distancias para experimentar una magnífica diversidad de oportunidades de consumo. Para su conveniencia, los florecientes 'distritos de entretenimiento urbano' concentran objetos, o al menos sus facsímiles, traídos de todas partes del mundo [...] Los residentes actúan crecientemente como turistas en sus propias ciudades" " (Lloyd, 2000: 7). La "localización del ocio" resultante ha estimulado, tanto como el turismo, la conversión de las ciudades o partes de ellas en lugares especializados de entretención (Hannigan, 1998).

2 El concepto de turismo "como si" de Richard Lloyd describe la continua mezcla de visitantes y residentes locales en los lugares de entretención en las ciudades.
El turismo coincide con -de hecho, es producto de- una cultura globalizada del consumo sostenida por trabajadores y consumidores altamente móviles. En Estados Unidos, el surgimiento de una clase cosmopolita global puede ser percibida a través de la proliferación de revistas de "estilos de vida urbanos" (Greenberg, 2000). En los '60, las revistas de estilos de vida fueron lanzadas en 60 áreas metropolitanas de Estados Unidos, número que ha crecido a más de 100 hacia el fin de siglo (Greenberg, 2000). Estas revistas son similares de ciudad en ciudad porque el público objetivo es invariable: una nueva clase media acomodada, compuesta en su mayor parte por baby boomers y su progenie bien educada y bien remunerada. En su estudio de revistas de Nueva York, Atlanta y Los Ángeles, Marian Greenberg (2000) encontró que desde comienzos de los '90, las personas en este estrato comparten una preocupación por "estilos de vida urbanos estrechamente definidos, orientados al consumo y políticamente conservadores" (25). El nuevo consumidor de clase media puede adquirir sofisticación instantánea degustando la cocina, bebiendo el vino, fumando los cigarros y comprando los autos y arte recomendados por una nueva especie de escritores y críticos especializados en dar consejos sobre estilos de vida.

Sassen (1994) ha documentado la concentración de una clase de trabajadores del sector servicios muy bien remunerados en las ciudades globales; sin embargo, en la actualidad la nueva clase global de los privilegiados "analistas simbólicos" se ha extendido prácticamente a todos los rincones del globo (Reich, 1991; Lury, 1997). El conjunto de bienes de consumo que los miembros de esta clase demandan es notoriamente similar en todas partes; por lo tanto, tiene sentido asumir que éstos tenderán a demandar -y por lo tanto, a reproducir- ambientes urbanos similares, dondequiera que vayan. Esta tendencia no es difícil de observar. Nueva York y el SoHo de Londres, así como los distritos de bodegas industriales en todas partes, han sido invadidos por una predecible combinación de tiendas te- 
máticas. La cocina étnica no sólo ha sido internacionalizada, sino además fetichizada, de modo que las mismas variedades de nouvelle cuisine étnica pueden ser encontradas en casi cualquier ciudad. Este desarrollo sugiere que la cultura globalizada del consumo opulento puede eventualmente reducir todas las ciudades a una monocultura monótona.

Sin embargo, los cosmopolitas no buscan las mismas cosas en todos los lugares donde van. Dado que muchos residentes y visitantes buscan aquello que es único, y numerosos visitantes viajan con propósitos distintos al turismo, la tendencia hacia la homogeneidad no es inevitable, y puede ser incluso improbable. Richard Lloyd (2000) distingue el surgimiento de una nueva cultura de la "neo-bohemia", liderada por residentes urbanos que asocian "los lugares desoladamente realistas con una energía creativa" (1). Esta nueva clase, sostiene, es responsable de la recuperación de "espacios aparentemente anacrónicos" (5) en inner cities tales como viejos distritos industriales y de bodegas, un desarrollo muy similar a la gentrificación de los márgenes de Londres, donde diseñadores y artistas han colonizado viejos portales comerciales, fachadas de tiendas y talleres (Fainstein, 2001).

Richard Florida (2002) ha demostrado que el grupo que denomina "la clase creativa" -profesionales de alto nivel educativo con habilidades intelectuales, analíticas, artísticas y creativas elitistas-, frecuentemente considera el estilo de vida como más importante que un empleo particular en la elección de un lugar para vivir. Los miembros de esta clase demandan interacción social, cultura, vida nocturna, diversidad y autenticidad, esta última definida como "edificios históricos, barrios consolidados, una escena musical única o atributos culturales específicos. Proviene de la mezcla de la argamasa urbana junto con edificios renovados, de la mixtura entre lo nuevo y lo viejo, el carácter de barrios de larga data y yuppies, modelos y bag ladies" (228). Florida señala que la clase creativa tiende a rechazar las "experiencias enlatadas": "Una cadena de restaurantes temáticos, un estadio deportivo con características de circo multimedia o un 'distrito de entretenimiento' y turismo predefinido son como paquetes turísticos: no se puede conseguir crear la experiencia o modular su intensidad; ésta es más bien impuesta". Lo que los miembros de la clase creativa demandan es "tener a mano la creación de la experiencia [de la ciudad] más que simplemente consumirla (232). Estas preferencias han dado origen a un movimiento globalizado que demanda mayores niveles de servicios urbanos, tanto públicos como privados (Clark, 2000a y 2000b).

\section{La ciudad fracturada como ciudad abierta}

Es difícil anticipar los tipos de lugares y experiencias hacia los cuales los turistas serán atraídos. Harlem, por ejemplo, se ha transformado en un destino popular para los turistas alemanes fascinados por los servicios religiosos afroamericanos y para otros turistas atraídos por un Nueva York "étnico" (Hoffman, 2000). Una proporción de turistas y residentes locales buscan lugares como éstos como una alternativa a la atmósfera artificial de los espacios turísticos enclávicos. Feifer (1985) ha propuesto que esta gente pueda ser llamada post-turistas (después de los "post-modernos"). A diferencia de los turistas corrientes, los post-turistas no desean fijar la mirada en los sitios turísticos sancionados oficialmente, en parte porque ellos ya han sobrellevado un continuo aluvión de objetos e imágenes turísticas proyectadas por la televisión, el cine, las revistas y otros medios de comunicación. Ya están hastiados de viajar incluso antes de salir de casa. Habiendo dejado de considerar cualquier "mirada" como privilegiada, los postturistas buscan una multitud de experiencias como un antídoto contra el aburrimiento.

Incluso dentro de los enclaves, el control social de los usuarios no es absoluto. Los postturistas, hartos de toda una vida de exposición al marketing temático están aptos para adoptar una postura irónica dentro de los 
confines de los "ambientes Disney". Lo que los post-turistas buscan en los festival malls y en los complejos de entretenimiento es pura diversión y escapismo; su postura irónica les permite buscar sus propias experiencias. Un segundo modo de resistencia es el rechazo a conformarse con los usos esperados. Como ha observado De Certeau (1984), "el espacio es un lugar ejercido" cuando, por ejemplo, "la calle geométricamente definida por la planificación urbana es transformada en espacio por los caminantes" (117).

Dado que los desarrolladores de los espacios enclávicos deben responder a gustos y preferencias cambiantes, las prácticas al interior de éstos deben ser menos estáticas e invariables de lo que generalmente se supone. Incluso en ciudades astilladas en enclaves y fragmentos, Graham y Marvin (2001) identifican varios modos de resistencia: los residentes de comunidades enrejadas ignoran o desafían regularmente sus common-interest associations; los jóvenes encuentran maneras de evadir las estrictas reglas impuestas dentro de los malls, y las normas impuestas por los dueños y administradores de los enclaves son a veces enfrentadas por protestas bien organizadas. El rechazo a conformarse puede ser afirmado incluso en circunstancias de extremo confinamiento. En su estudio sobre el turismo en India, Edensor (1998) encontró que a pesar de los mejores esfuerzos por parte de los guías turísticos para proteger a los grupos bajo su cargo de encuentros imprevistos, la mezcla de espacios a menudo promovía los recorridos casuales y las caminatas y vagabundeos por calles, mercados y cafés al aire libre. Los miembros de los paquetes turísticos salían a veces a deambular libremente, ocupando la zona limítrofe del anonimato propia del flaneur (Urry, 1990).

Esto sugiere un tercer modo de resistencia, el cual está disponible en todas las ciudades, pero sobre todo en aquellas con mayores problemas: escapar de los enclaves estrecha- mente regulados. Casi en todas partes, las ciudades que desean atraer visitantes han invertido fuertemente en instalaciones públicas como parques, fuentes, jardines y arte público. Hay también distritos centrales de negocios, calles pobladas con pequeños negocios y tiendas y vecindarios. Los enclaves existen al interior de una compleja estructura urbana que entrega a visitantes y residentes locales por igual numerosas oportunidades para deambular. En un mismo día, un visitante o residente local puede probar "entretenimientos Disney", ir a una exposición de Monet, caminar a través de un barrio histórico y terminar en un restaurante étnico (el cual puede ser un local de barrio, barato, u otro más caro, que sirva una versión globalizada y nouvelle de la cocina étnica en cuestión). La ciudad es un crisol que reúne los circuitos de capital y cultura globalizadas con lo local y lo excéntrico, lo cosmopolita con lo provinciano.

Los enclaves turísticos han proliferado a través del mundo. Graham y Marvin (2001) predicen la propagación global de ciudades de fantasía que entremezclan comercio minorista, restaurantes y bares, salas de espectáculo, cines y teatros IMAX, hoteles, centros de video y de realidad virtual y otras diversiones en un ambiente de puro consumo y entretención. Incluso ahora, quien viaje por el mundo puede encontrar versiones de estos complejos de entretenimiento diseminados a lo largo del globo (lyer, 2000). No obstante, como Graham y Marvin (2001) observan, "la vida urbana es más diversa, variada e impredecible que lo que sugieren las certezas comunes, inspiradas en las distopias urbanas estadounidenses" (392). Un examen de los espacios turísticos revela que la fractura de los espacios de las metrópolis postmodernas puede crear diversidad y diferencia, más que monotonía y uniformidad. Como en el pasado, las ciudades del futuro serán muy probablemente lugares que combinen orden y caos en una mezcla constantemente cambiante e impredecible. Eso es lo que las hace tan fascinantes. 


\section{Referencias bibliográficas}

Artibise, A. (2003). "Tourism Infrastructure of a Post-Industrial City: A Case Study of Vancouver, British Columbia". Judd, D. R. (ed.), The Infrastructure of Play: Building the Tourist City. Armonk, New York: M.E. Sharpe.

Baudrillard, J. (1998). The Consumer Society: Myths and Structures. Thousand Oaks, CA: Sage Publications.

Beauregard, R. A. (1993). Voices of Decline: The Postwar Fate of American Cities. New York: Blackwell.

Boyer, C. (1994). The City of Collective Memory: Its Historical Imagery and Architectural Entertainments. Cambridge, MA: The MIT Press.

De Certeau, M. (1984). The Practice of Everyday Life. Berkeley: University of California Press.

Clark, T. N. (2001a). "Trees and Real Violins: Building Post-Industrial Chicago". Paper presented to the Chicago Urban Politics Workshop (February 16). (2001b). "Amenities Drive Urban Growth". Paper presented at the Annual Meeting of the American Political Science Association, San Francisco, California. August.

Cocks, C. (2001). Doing the Town: The Rise of Urban Tourism in the United States, 1859-1915. Berkeley: University of California Press.

Dear, M. J. (ed.) (2002). From Chicago to L.A.: Making Sense of Urban Theory. Thousand Oaks, CA: Sage Publications.

Edensor, T. (1998). Tourists at the Taj: Performance and Meaning at a Symbolic Site. New York: Routledge.

Edsall, T. B. \& M. D. Edsall (1991). Chain Reaction: The Impact of Race, Rights, and Taxes on American Politics. New York: W. W. Norton.

Ehrlich, B. \& P. Dreier (1999). "The New Boston Discovers the Old: Tourism and the Struggle for a Livable City". Judd, D. J. \& S. S. Fainstein (eds.), The Tourist City. New Haven: Yale University Press.
Fainstein, S. S. (2001). The City Builders. Lawrence, KS: University Press of Kansas.

Featherstone, M. (1994). "City Cultures and Post-modern Lifestyles". Amin, A. (ed.), Post-Fordism: A Reader. Oxford/ Cambridge: Blackwell.

Feifer, M. (1985). Going Places. London: Macmillan.

Florida, R. (2002). The Rise of the Creative Class. New York: Basic Books.

Graham, S. \& S. Marvin (2001). Splintering Urbanism: Networked Infrastructure, Technological Mobilities and the Urban Condition. London/New York: Routledge.

Greenberg, M. (2000). "Branding Cities: A Social History of the Urban Lifestyle Magazine". Urban Affairs Review, 36, 2: 228-263.

Hall, P. (1996). Cities of Tomorrow. Cambridge, MA: Blackwell.

Hannigan, J. (1998). Fantasy City: Pleasure and Profit in the Postmodern Metropolis. New York: Routledge.

Harvey, D. (1994). "Flexible Accumulation through Urbanization: Reflections on 'Postmodernism' in the American City". Amin, A. (ed.), Post-Fordism: A Reader. Oxford/ Cambridge: Blackwell.

(2001). Spaces of Capital:

Towards a Critical Geography. New York: Routledge.

Hiernaux-Nicolás, D. (2003). "Tourism and Strategic Competitiveness: Infrastructure Development in Mexico City". Judd, D. R. (ed.), The Infrastructure of Play: Building the Tourist City. Armonk, New York: M.E. Sharpe.

Hoffman, L. M. (2000). "Tourism and the Revitalization of Harlem". Research in Urban Sociology, Vol. 5. Greenwich, Conn.: JAI Press.

lyer, P. (2000). The Global Soul: Jet-Lag, Shopping Malls and the Search for Home. London: Bloomsbury.

Judd, D. R. \& M. Parkinson (eds.) (1990). Leadership and Urban Regeneration: Cities in North America and Europe. Thousand Oaks, CA: Sage Publications.

Judd, D. R. (1999). "Constructing the Tourist Bubble". Judd, D. R. \& S. S. Fainstein 
(eds.), The Tourist City. New Haven: Yale University Press.

Lefebvre, H. (1991). The Production of Space. London: Blackwell.

Levine, M. V. (2003). "Tourism Infrastructure and Urban Redevelopment in Montreal". Judd, D. R. (ed.), The Infrastructure of Play: Building the Tourist City. Armonk, New York: M.E. Sharpe.

Lloyd, R. (2000). "Grit as Glamour: Neo-Bohemia and Urban Change". University of Chicago (unpublished. ms.).

Lury, C. (1997). "The Objects of Travel". Rojek, C. \& J. Urry (eds.), Touring Cultures: Transformations of Travel and Theory. London/New York: Routledge.

Reich, R. B. (1991). The Work of Nations: Preparing Ourselves for $21^{\text {st }}$ Century Capitalism. New York: Knopf.

Rothman, H. K. \& M. Davis (eds.) (2002). The Grit Beneath the Glitter. Berkeley: University of California Press.

Sassen, S. (1994). Cities in a World Economy. London: Pine Forge Press.
Sassen, S. \& F. Roost (1999). "The City: Strategic Site for the Global Entertainment Industry". Judd, D. R. \& S. S. Fainstein (eds.), The Tourist City. New Haven: Yale University Press.

Soja, E. W. (1989). Postmodern Geographies: The Reassertion of Space in Critical Social Theory. New York: Verso.

Thompson, E. P. (1967). "Time, Discipline, and Industrial Capitalism". Past and Present, 38, as quoted in Zukin, S., Landscapes of Power: From Detroit to Disney World. Berkeley: University of California Press, 1991.

Urry, J. (1990). The Tourist Gaze: Leisure and Travel in Contemporary Societies. London: Sage Publications.

van den Berg, J. et al. (2003). "The Infrastructure of Urban Tourism: A European Model?" Judd, D. R. (ed.), The Infrastructure of Play: Building the Tourist City. Armonk, New York: M.E. Sharpe.

Withey, L. (1997). Grand Tours and Cook's Tours: A History of Leisure Travel 1750 to 1915. New York: William Morrow and Company. 